\title{
Study on the Heritage Corridor Construction of the Western Han Dynasty Mausoleums Region
}

\author{
Yu Dong1, Yan Jiang1, Dongji Quan², Haixia Zhu² \\ ${ }^{1}$ Xi'an City Planning and Design Institute, Xi'an, China \\ ${ }^{2}$ College of Urban and Environmental Sciences, Northwest University, Xi'an, China \\ Email: dongyu_work@126.com
}

How to cite this paper: Dong, Y., Jiang, Y., Quan, D. J., \& Zhu, H. X. (2022). Study on the Heritage Corridor Construction of the Western Han Dynasty Mausoleums Region. Current Urban Studies, 10, 55-72. https://doi.org/10.4236/cus.2022.101004

Received: January 4, 2022

Accepted: February 18, 2022

Published: February 21, 2022

Copyright (c) 2022 by author(s) and Scientific Research Publishing Inc. This work is licensed under the Creative Commons Attribution International License (CC BY 4.0).

http://creativecommons.org/licenses/by/4.0/

(c) (i) Open Access

\begin{abstract}
Due to the large scale and the complex cultural structure, the Great Site can be easily affected during the process of city development, which leads to an imbalance and inequality trend from the regional perspective. Based on the research about conservation and utilization of the linear heritage at home and abroad, the theoretical basis and method of heritage corridor planning in the Western Han Dynasty Mausoleums were discussed in this paper. The current research on the heritage corridor is mainly concerning the legacy which is in the linear form itself, such as the Canal and the Wall, etc. There are few studies on constructing the heritage corridor by connecting the heritage points with linear characteristics. Based on the analysis of the basic conditions about the heritage corridor construction, this paper determines the theoretical framework of heritage corridor construction from the aspects of concept connotation, system elements and planning system. Based on the theoretical framework, the planning area was determined through suitability analysis. At the same time, the construction path of the heritage corridor was studied from the three aspects of Patch-Corridor-Matrix. It aims to strengthen the interaction between the Great Site and the surrounding area by the planning, so as to promote the heritage activation, as well as the development of the region.
\end{abstract}

\section{Keywords}

Heritage Corridor, Construction, Western Han Dynasty Mausoleums

\section{Introduction}

The nine Mausoleums of the Western Han Dynasty are located at the Xianyang Tableland in the center of Guanzhong Plain. They are significant evidence to understand politics, economy, culture and life in the Western Han Dynasty, which 
is called the "Oriental Pyramid". The nine Mausoleums jointly constitute the Western Han Dynasty Mausoleums Region as well as the study area, which is the junction of Xi'an and Xianyang. The region shows the salient features of urban and rural transitional zones in the process of urban development and construction.

In January 2014, the State Council officially approved the establishment of Xi Xian New Area in Shaanxi province, which is the core of the Guanzhong-Tianshui Economic Zone and will become the new engine of west part. As the main functional area of Xi'an Metropolis in the future, the urban expansion is inevitable. The suburban natural areas on the north of Weihe River would also gradually become developing areas with dense human economic activities. With the condition of new regional development, the Western Han Dynasty Mausoleums Region will face greater challenges as the changing of urban and rural structure. Based on the perspective of regional harmonious development, this paper proposed the multi-dimension and multidisciplinary intersection method that is to say the heritage corridor construction to solve the contradiction between protection and development in the study area.

The article is divided into five parts, the first part gives an overview of the heritage corridor, the second and third parts sort out the study area and the resources distributed therein, the fourth part constructs a theoretical framework for heritage corridor planning, and finally, taking the Western Han Dynasty Mausoleums as an example, the planning content is studied and analyzed based on the different attributes of the patch, corridor and matrix on the basis of the delineated scope.

\section{Heritage Corridor-Comprehensive Exploration of Protection and Utilization of the Heritage Area}

The research of protection and utilization for the heritage area is relatively mature at abroad. Regis P. pointed out that there is a dialectical relationship between protection and development of the heritage, neither arbitrary development, nor too much command (Regis, 2015). To protect the 17th-century Dutch military defense heritage from being affected by the urban construction, Landscape planning is carried out in the heritage area, using the green gallery, buffer zones and other ecological Landscape facilities to keep the heritage isolated from the high-strength construction activities of the city, which also beautify the landscape environment of the heritage (Lindsey, 2019).

With great attention to the interaction between the heritage and the people, the United States built the first heritage corridor of the world in 1984-the Erie canal national heritage corridor, which is the earliest exploration of heritage corridor stepping from theory to practice (Eugster, 2003). The United States government put forward the Erie Canal National Heritage Corridor protection and Management Plan in 2006, which points out that the whole Heritage Corridor planning includes: the protection of historical and cultural resources, natural land- 
scape resources protection and the improvement of chronic open system, the construction of commentary system and the corresponding marketing strategy and the Management system (Xi \& Chen, 2013; Gong \& Zhang, 2014).

Study of heritage corridors in Asia, such as the taj mahal heritage corridor of the Yamuna River (Harkness \& Sinha, 2004), Indonesia Medan heritage corridor proved that the heritage corridor plays an important role in improving public participation (Ginting, 2016), reshaping the regional image, driving the development of tourism and optimizing the environment of the landscape, which effectively promotes the social and economic development of the region (Denis, 2021; Ewa et al., 2019).

The heritage corridor was systematically studied by domestic scholars in recent years, mainly including the following three aspects: 1) The four indispensable parts of heritage corridor construction system are the protection of cultural heritage, the greenway system building, traffic organization and system organization (Wang \& Sun, 2001; Wang, 2015). 2) The suitability analysis is the key method to the planning of the heritage corridor (Yu et al., 2005; Zhan et al., 2015). 3) As for the regional development, because of the properties of cultural resources and linear landscapes, the heritage corridor has the congenital advantage of the development of cultural tourism industry, through which the fresh vitality is injected into the region (Zhong, 2021).

\section{General Situation of the Western Han Dynasty Mausoleums}

There are 11 parts within the Western Han Dynasty Mausoleums, which were listed as "The 5th batch of National Key Cultural Relics Protection Units" in 2001. Nine of them are located in Xianyang Tableland north of Weihe River in a linear shape alone the Zhengguo Canal. From east to west, there are Yang Mausoleum, Chang Mausoleum, An Mausoleum, Yi Mausoleum, Wei Mausoleum, Kang Mausoleum, Yan Mausoleum, Ping Mausoleum and Mao Mausoleum as shown in Figure 1. The west beginning is Xianyang-Tableland, and the east end is Gao Mausoleum District. It is about 40 kilometers long from east to west and 13 kilometers wide from north to south (Yang, 2009).

Xianyang Tableland was also known as Five-Mausoleums Tableland because of the mausoleum towns. As an important part of the imperial mausoleum, the setting of the mausoleum town has significant influence in stabilizing the regime, promoting the economy and strengthening the military defense. In addition, the construction of the imperial mausoleum is closely related to the surrounding natural environment, and is affected by the geographical condition, vegetation and water condition. Therefore, it is necessary to consider the surrounding environment during the study of the Western Han Dynasty Mausoleums. In this paper, the planning scope in the protection planning for Xianyang Tableland is determined as the study area, as shown in Figure 2. 


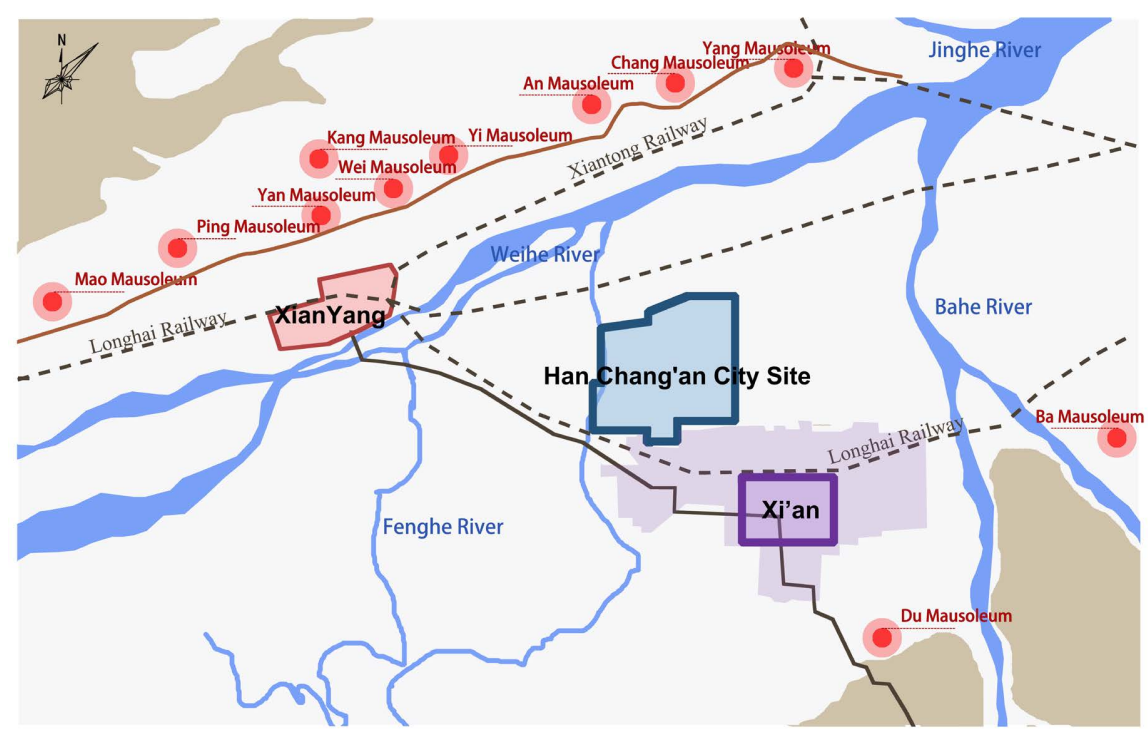

Figure 1. Position diagram. Source: authors.

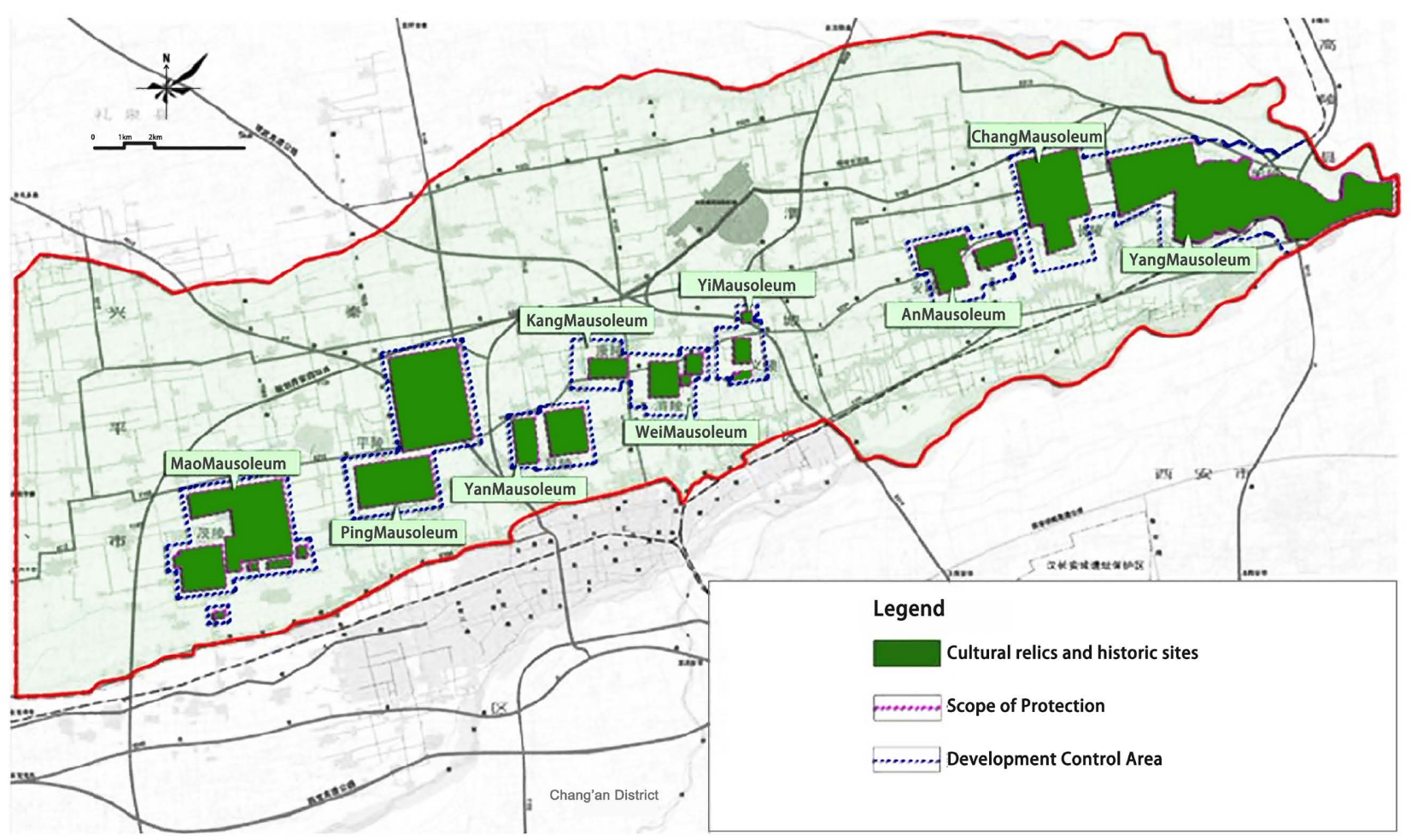

Figure 2. Study area. Source: the protection planning for Xianyang Tableland.

\section{The Conditions of the Heritage Corridor Construction of the Study Area}

\subsection{Related Research Foundations}

Some scholars' research on the protection and utilization of the Western Han Dynasty Mausoleums Region has laid the foundation for this paper. 
In terms of heritage protection and urban and rural development, Zhao Z. S. suggested that in order to better protect the heritage region, it is necessary to delimit the "culture area" which is able to coordinate the contradiction between heritage protection, industrial and agricultural production and the large infrastructure construction from the perspective of the whole district (Zhao, 2007). Yan Y. J. studied the contradiction between the Mausoleums and natural environment from the perspective of historical geography and environmental changes and thought there was profound influence between each other (Yang \& $\mathrm{Xu}, 2013)$.

In terms of heritage protection and industrial development, the consideration of building the tourist corridor, the planning strategy of urban agricultural and the proposition to cultivate cultural industry chain were put forward ( $\mathrm{Li}$ et al., 2020; Zhu, 2016).

The proposed concepts such as "cultural district", "tourism band" and "tourism corridor" toward the Western Han Dynasty Mausoleums have certain representative but lack of systematic research. Based on the study above, the author believes that it is scientific and reasonable attempt to construct the heritage corridor to solve the contradiction between the heritage protection and the regional development (Boley \& Gaither, 2016; Yang, 2020).

\subsection{Conditions of the Study Area}

\subsubsection{Natural Environment and Resources}

The Five-Mausoleums Tableland of the study area belongs to the topography of the loess plateau. The elevation is between 405 and 450 meters, and the slope is less than $15 \%$. The area development degree is low because the district cannot undertake large-scale construction activity, which leads to a better development condition. The study area belongs to Weihe River system, which contains the Weihe River and its tributary rivers.

The study area is mainly agricultural land, and the surrounding area is mostly farmland. The tree species of Mao Mausoleum and Yang Mausoleum have certain order with planning and makes the landscape conditions become the unique characteristics of the five-mausoleums Tableland. Which contributes to the development of the urban agriculture and culture tourism in the future, additionally become a natural advantage for the construction of the heritage corridor (Figure 3).

\subsubsection{The Historical and Cultural Resources}

In order to build the core elements of heritage corridor system, the historical and cultural resources of the Western Han Dynasty Mausoleums can be divided into tangible cultural elements as shown in Table 1 and intangible culture elements as shown in Table 2, which also have different ways of protection and utilization in the future.

1) The precondition for organizing the tangible culture elements is that, during the construction of the heritage corridor, can be expressed in space and 


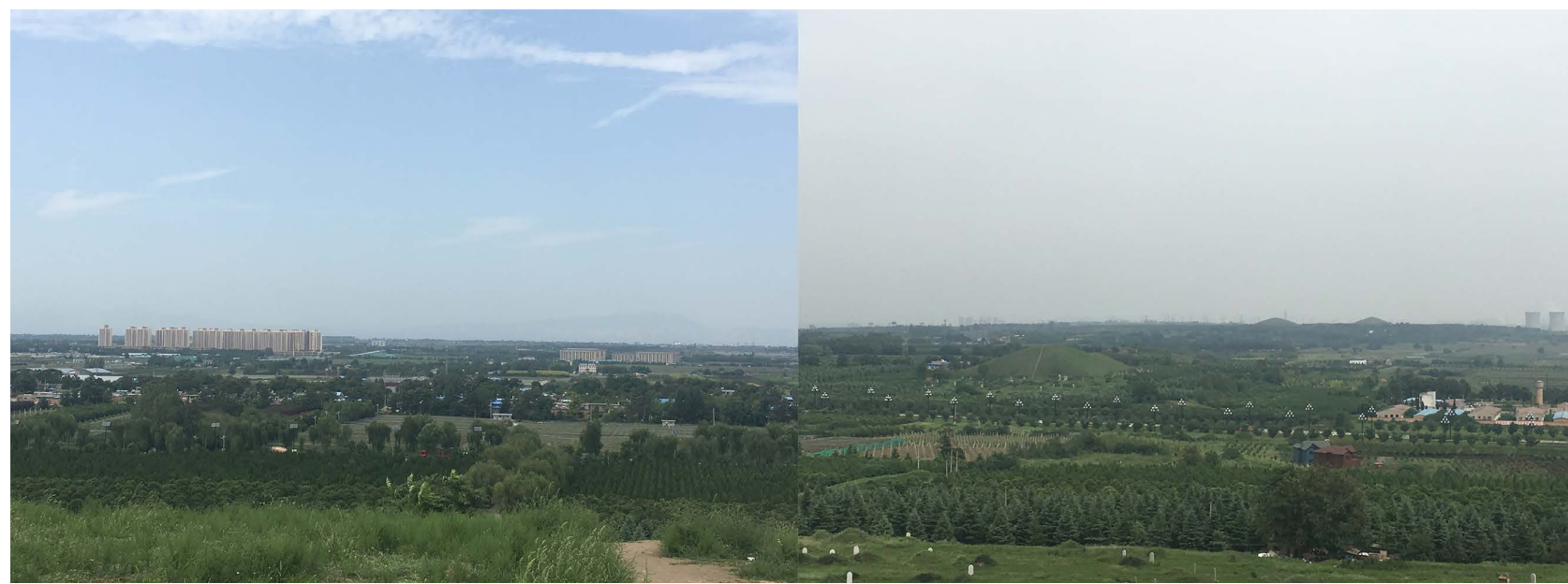

Figure 3. Surrounding landscape environment of the study area. Source: authors' photography.

Table 1. The types of tangible cultural elements in the study area.

\begin{tabular}{|c|c|}
\hline Major Categories & Specific Contents \\
\hline Mausoleum Sites & $\begin{array}{l}\text { Imperial Cemetery (heap earth over mound), } \\
\text { Funeral Objects (Pei Zang Mu), Mausoleum Town (Ling Yi), } \\
\text { Vault (Cong Zang Keng) }\end{array}$ \\
\hline Architectural Relics & $\begin{array}{l}\text { The site wall (Qiang Zhi), door que (Men Que), } \\
\text { lay and house construction sites (Qin Bian Dian), etc }\end{array}$ \\
\hline Engineering Sites & $\begin{array}{l}\text { Sima Road, Mausoleum Path (Shen Dao), } \\
\text { Jiao Path (Jiao Dao), Irrigation Canal Relics }\end{array}$ \\
\hline Landscape Sites & The relics sites of artificial lakes, pond \\
\hline $\begin{array}{l}\text { Movable } \\
\text { Historical Relics }\end{array}$ & $\begin{array}{l}\text { Grave goods (Pei Zang Pin), pillars (Zhu Shi), } \\
\text { tiles accumulation }\end{array}$ \\
\hline
\end{tabular}

Source: authors.

Table 2. The types of intangible cultural elements in the study area.

\begin{tabular}{cc}
\hline Major Categories & Specific Contents \\
\hline $\begin{array}{c}\text { The historical } \\
\text { Figures and allusions } \\
\text { The Han dynasty } \\
\text { symbol system } \\
\text { Literary works } \\
\text { History, folk custom }\end{array}$ & $\begin{array}{c}\text { The lives of the emperors and the queens, } \\
\text { important historical relics, the significant work }\end{array}$ \\
Stone carvings, brick portraits, \\
figurines (Tao Yong) \\
Articles, poems, calligraphy
\end{tabular}

Source: authors.

become an important part of the corridor space entity.

2) Intangible cultural elements mainly occupy the important position in the display and commentary system. It is able to increase the area of readability and 
enrich the connotation of the corridor through the form of text and graphics.

\section{The Theoretical Framework of the Heritage Corridor Construction}

\subsection{Analysis of the Heritage Corridor Contents}

Because the heritage corridor has the characteristics of flexible scale, complicated content and comprehensive functions, the difference of characteristics between different types of heritage corridor is significant. The heritage corridor that the authors studied in this paper is constituted of big relics of the emperor mausoleums, the scale of each emperor mausoleum is large, and its protection and utilization is complex, which makes it necessary to further resolve the concept of heritage corridor (Wu \& Wang, 2020; Chu et al., 2019).

First of all, from the perspective of the method, this paper takes "heritage corridor" as a planning method to solve the development problems of the Western Han Dynasty Mausoleums, and to emphasize the balance of heritage activation and regional economic development in the planning process, which can be also regarded as the more detailed and specific type of regional planning. At the same time, the core goal of the heritage corridor construction of this paper is forming the benign interaction of the protection and utilization, which can be seen as an important part of heritage conservation planning (Li, 2016).

Secondly, from the perspective of contents, by combing the domestic and foreign related research, heritage corridor planning contents generally include cultural heritage protection, the green space system, road system, commentary system. Because the study area of this paper is located in the suburbs and in a kind of discontinuous corridor form, the scales of heritage corridor will be more flexible. As the superposition of the historical and cultural information in different periods, the contents will be more complex. Therefore, the contents should also include the organization of the spatial pattern, the adjustment of the village function, the industry organization and so on in addition to the four basic contents. The more comprehensive the contents system is, the better that the contradiction between protection and development of site can be resolved.

\subsection{The Elements of the Heritage Corridor System}

Corresponding to the "patch-corridor-matrix" mode of landscape ecological theory, the elements of the heritage corridor can be analyzed from the three levels of "point-line-plane" (Liang, 2013). The Point refers to various historical and cultural resource points which ordinarily contain abundant historical information. The Line means the shape of the corridor itself. Some of the main roads or rivers in the corridor have the function of passages or barriers, which are the reinforcement of the corridor forms. The Plane refers to the facet space including the natural environments where the heritage site is located in, and it mainly reflected in the spatial pattern and land texture (Figure 4). 


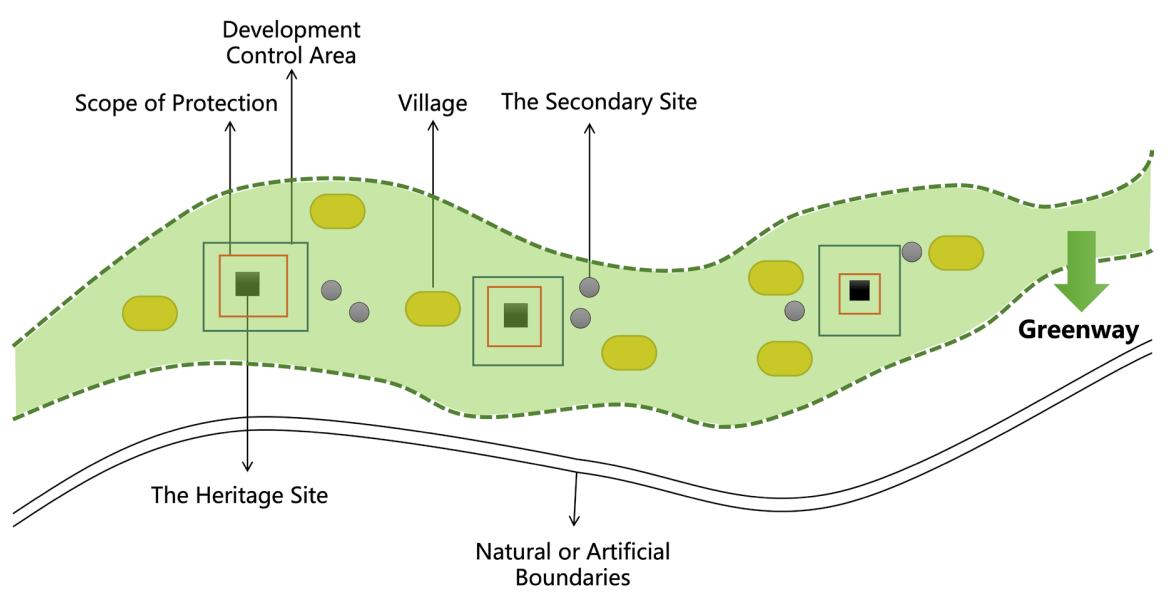

Figure 4. Schematic diagram of the heritage corridor system elements. Source: authors.

\subsection{The Heritage Corridor Construction Objective and System}

\subsubsection{Planning Objective}

Based on the regional coordinated development, five goals have been put forward in the process of heritage corridor planning in this paper: 1) Protecting the cultural heritage, and excavating the value of the historical and cultural resources, makes the heritage "alive"; 2) Updating the landscape environment, building the green corridors and intensifying the ecological ground substance; 3) Increasing the industrial vitality and enhancing the regional economy; 4) Enriching recreational activities by improving the sound interpretation system to attract more and more people; 5) Coordinating urban development and promote positive interaction.

\subsubsection{Planning System}

According to the connotation analysis and system components of the heritage corridor, combining the principle of "patch-corridor-matrix", the planning system of heritage corridor of the study area was constructed (Tang, 2016; Wang, 2016).

1) Patch level: a) Main purpose of building the heritage corridor is to protect the cultural heritage reasonably and effectively; b) In order to determine the village layout status, the relocation and retention objects according to the type of the heritage and the size of the village and the basic scale of the new type of community should be studied; c) The spatial distribution of the cultural industry is determined by selecting the appropriate cultural industry types.

2) Corridor level: a) Based on the constraints of the status and the requirements of regional development, the spatial pattern of the heritage corridor is organized on the macro perspective; b) The public transport accessibility and the organization of the chronic system are both concerned to organize the traffic system from the external and internal perspectives. c) Organization of interpretation system is one of the core contents of the heritage corridor which is necessary to define the emphasis of each node and determine the interpretation theme 
of different nodes.

3) Matrix level: For the heritage corridor, the continuous green space system provides a continuous base background for the different patch elements. This paper points out that combining the historical and cultural background, the ecological demand and the social economic demand, the green corridor space can not only have the ecological effect, but also have the economic effects by the treatment of "conservation" or "update" on the existing cultivated land (Figure 5).

\section{Main Contents of the Heritage Corridor Construction}

\subsection{Delimiting the Range of the Heritage Corridor}

The routes of delimiting the heritage corridor range are shown in Figure 6. First of all, the resource investigation should be conducted in the Western Han Dynasty Mausoleums Region covering selecting and evaluating the representative heritage sources. Secondly, the evaluation on the heritage corridor suitability should be carried out in the whole study area, so as to determine the most suitable area for the heritage corridor construction, and furthermore provide the basis for delimiting the range of the heritage corridor.

The heritage corridor suitability analysis is based on the minimum cumulative resistance (MCR) model. This method was used earliest for simulating the spatial resistance and analyzing the cost that produced in the process of species

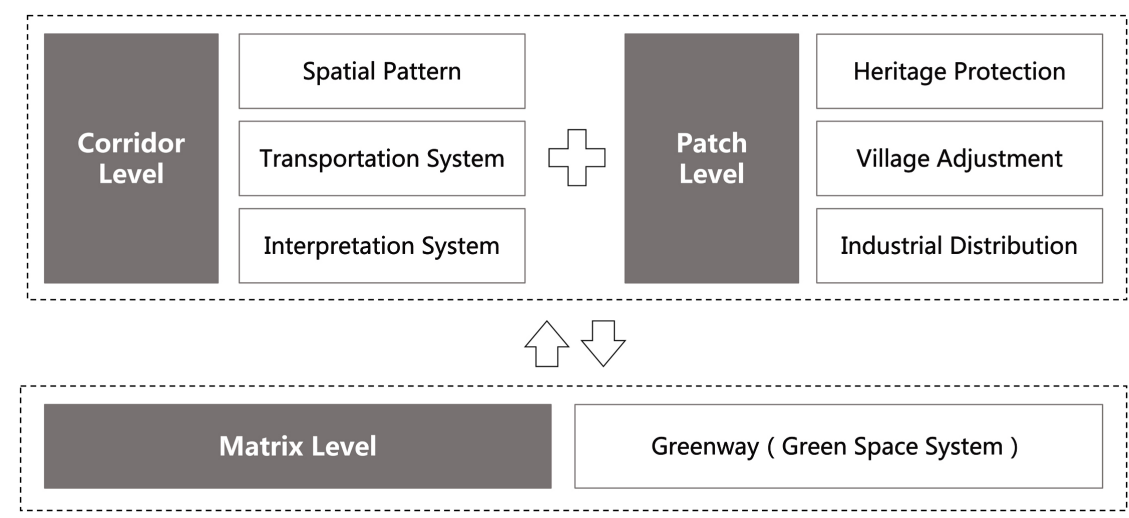

Figure 5. Planning system of the heritage corridor. Source: authors.

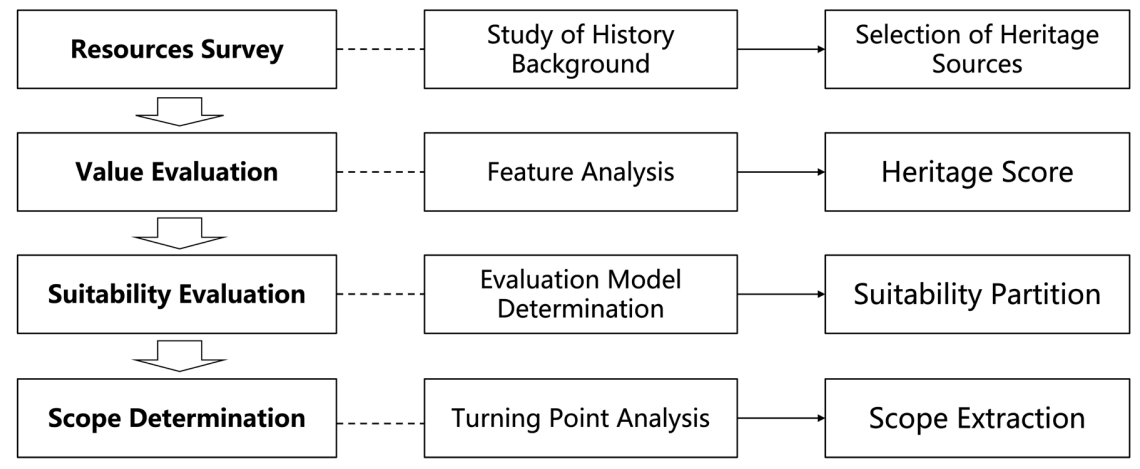

Figure 6. The basic idea of delimiting the heritage corridor range. Source: authors. 
space activities. In the study, MCR method is mainly used to simulate the spatial resistance distribution of different environmental factors arriving to the heritage source. The resistance size is directly proportional to the suitability of the regional heritage corridor, which can be realized via the cost distance module of ArcGIS.

Firstly, the cost grid is built relying on the different factors of land use types, roads, water system, and combining with the relative resistance coefficient by using ArcGIS software platform (Figure 7), and the suitability evaluation results of horizontal space related to the cultural activities in the heritage area can be obtained through the cost-distance calculation (Figure 8).

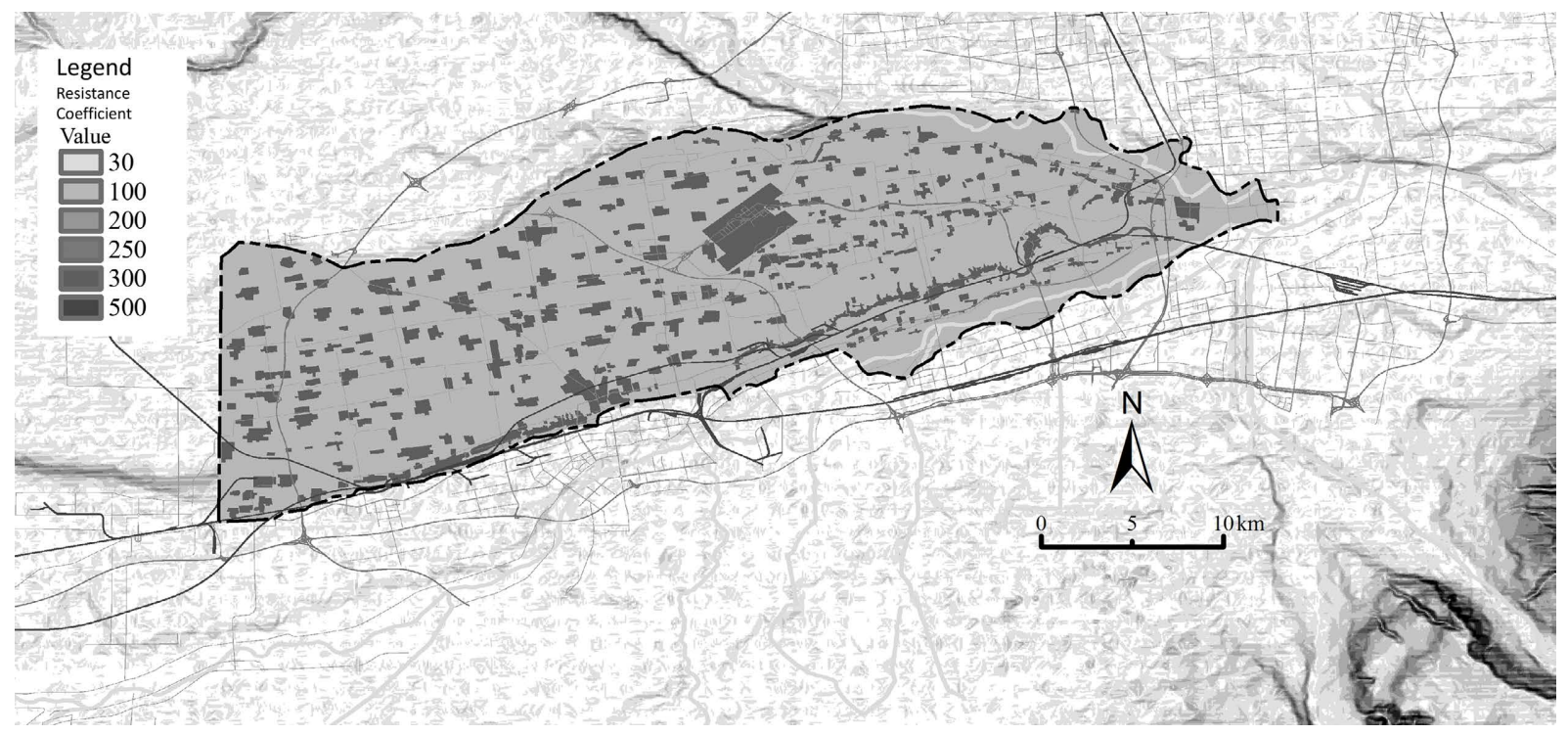

Figure 7. Integrated cost grid. Source: authors.

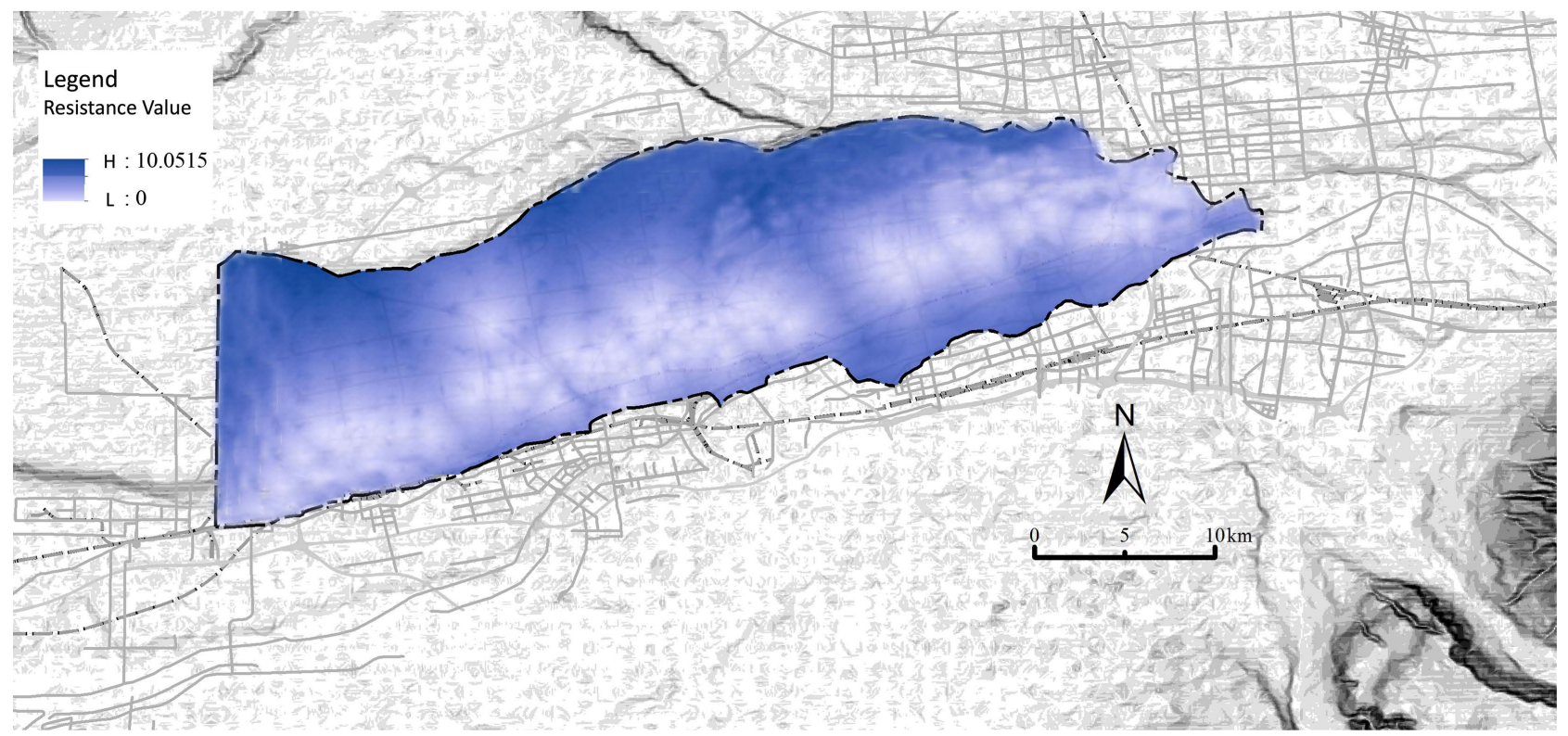

Figure 8. Suitability evaluation of heritage corridor. Source: authors. 
Based on the suitability evaluation, the results were analyzed by the Geostatistical Analyst tool of ArcGIS, and the raster was reclassified according to the turning points of the accumulated resistance, with turning point values of 0.75 , $2.75,4.02$, and 6.03 . The area of higher suitability, i.e., with a turning point value of 2.75 , is the main planning area of the heritage corridor identified in this paper, as shown in Figure 9.

\subsection{The Contents of the Patch Planning}

\subsubsection{Heritage Protection}

At present, legal protection zones for the nine Western Han Mausoleums are determined. The delimiting of the protection scope and the construction control zone means that there are strict requirements for the protection, construction and management. On this basis, methods like "expanding the scope and making detailed control requirements" should be taken to protect the environmental features of the heritage, so as to make the entire heritage corridor as environmental features coordination area, as shown in Figure 10. Construction activities are prohibited within protection scope, are restricted by building control zone and are controlled by landscape coordination zone. Expanding the scope of influence is not to obstruct the construction of the road, but to elaborate the construction control requirements, and to strengthen the supervision while leaving some space for the construction activities.

\subsubsection{Village Stationing Adjustment}

Formed in the process of historical evolution and the development, village settlement is one of the important parts in the study area. Some villages have more than one hundred years of history, which are characteristic elements of the heritage corridor. The Mausoleum City is representative because the mausoleum

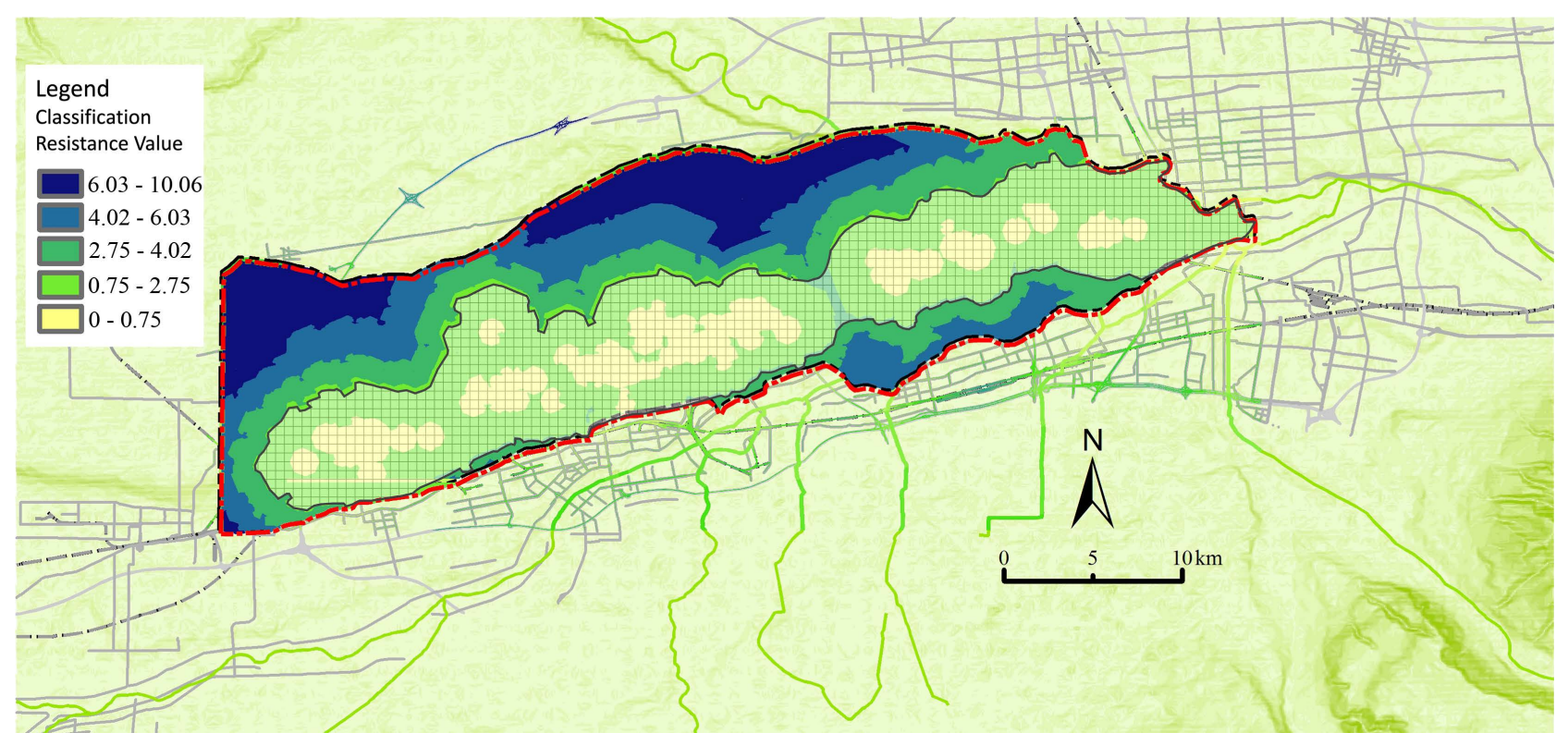

Figure 9. Suitability partition and main planning scope. Source: authors. 


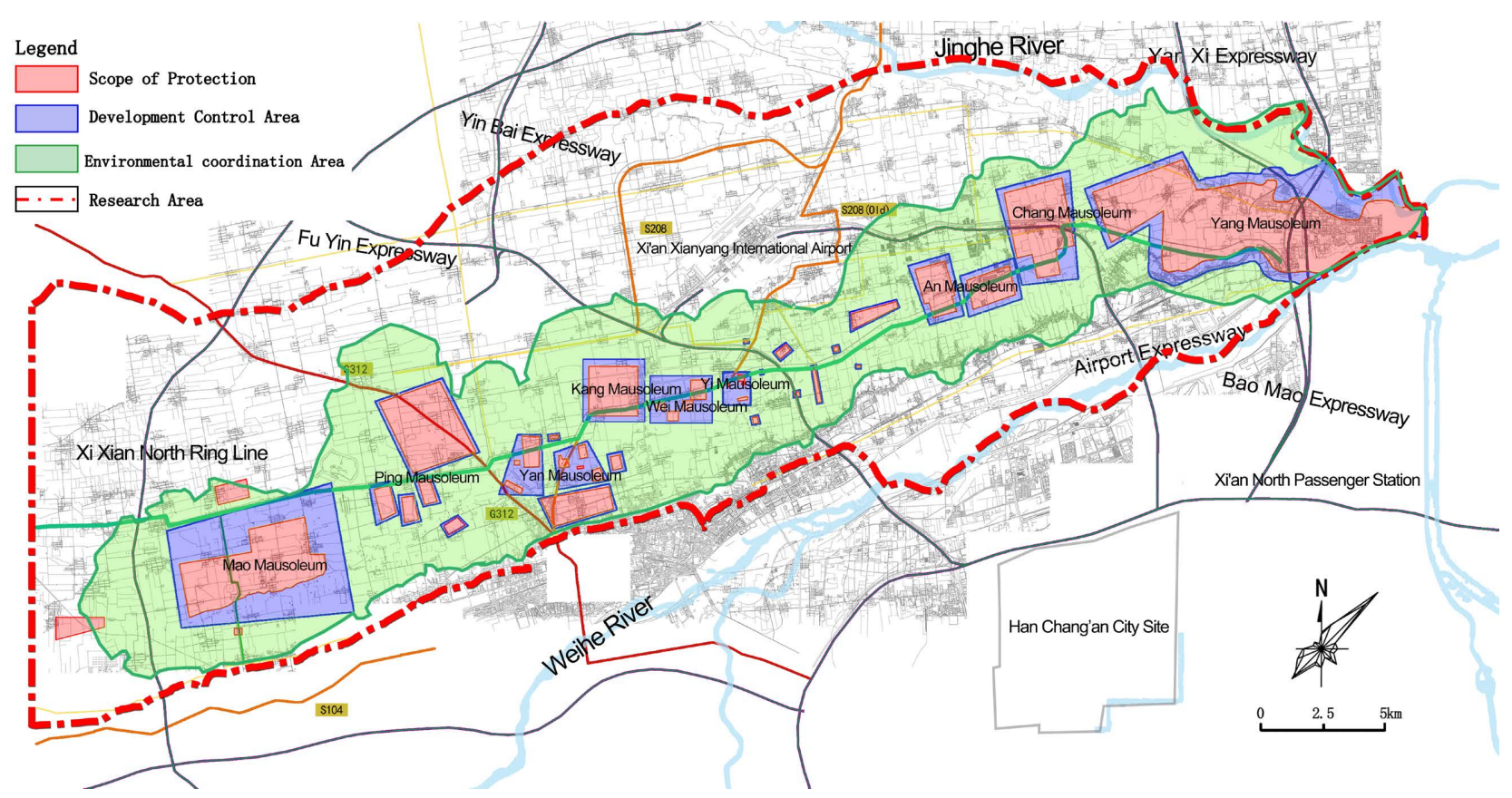

Figure 10. Environmental coordination area. Source: authors.

itself is a populated area. Therefore, distinctive, long lasted villages should not be dismantled but be exploited to form small characteristics plaque of local area.

At present, the distribution of villages in the planning area is relatively scattered, and many of them are located in the surrounding area of the mausoleums. The construction of villages and residents' activities inevitably conflict with the protection of the cultural relics. In order to protect the mausoleums and their environments, and to control the migration of the population at a minimum number, different control policies and measures of villages and population should be taken within the scope the heritage corridor. The villages and population of the mausoleum area will most likely be relocated. Because the Mausoleum Cities themself carry the residence function, in order to preserve the historical information, the villages and population of the protection area are basically remained the status. Considering the employment and agricultural activities of new housing tenants, new homes will be arranged outside the heritage corridor to as far as possible within the town. Whether the villages and population in the protected area of the Mausoleums are partially or wholly removed will be further determined based on the actual situation and the will of the residents (Figure 11).

\subsection{The space Organization of the Corridor}

\subsubsection{Spatial Pattern Organization}

Through land use types, the status of the construction of heritage corridor is known, as shown in Figure 12. Because the areas of the mausoleums take up most of the area and villages construction are scattered, land use need to be integrated to solve the problems of single and rough utilization of the territory. 


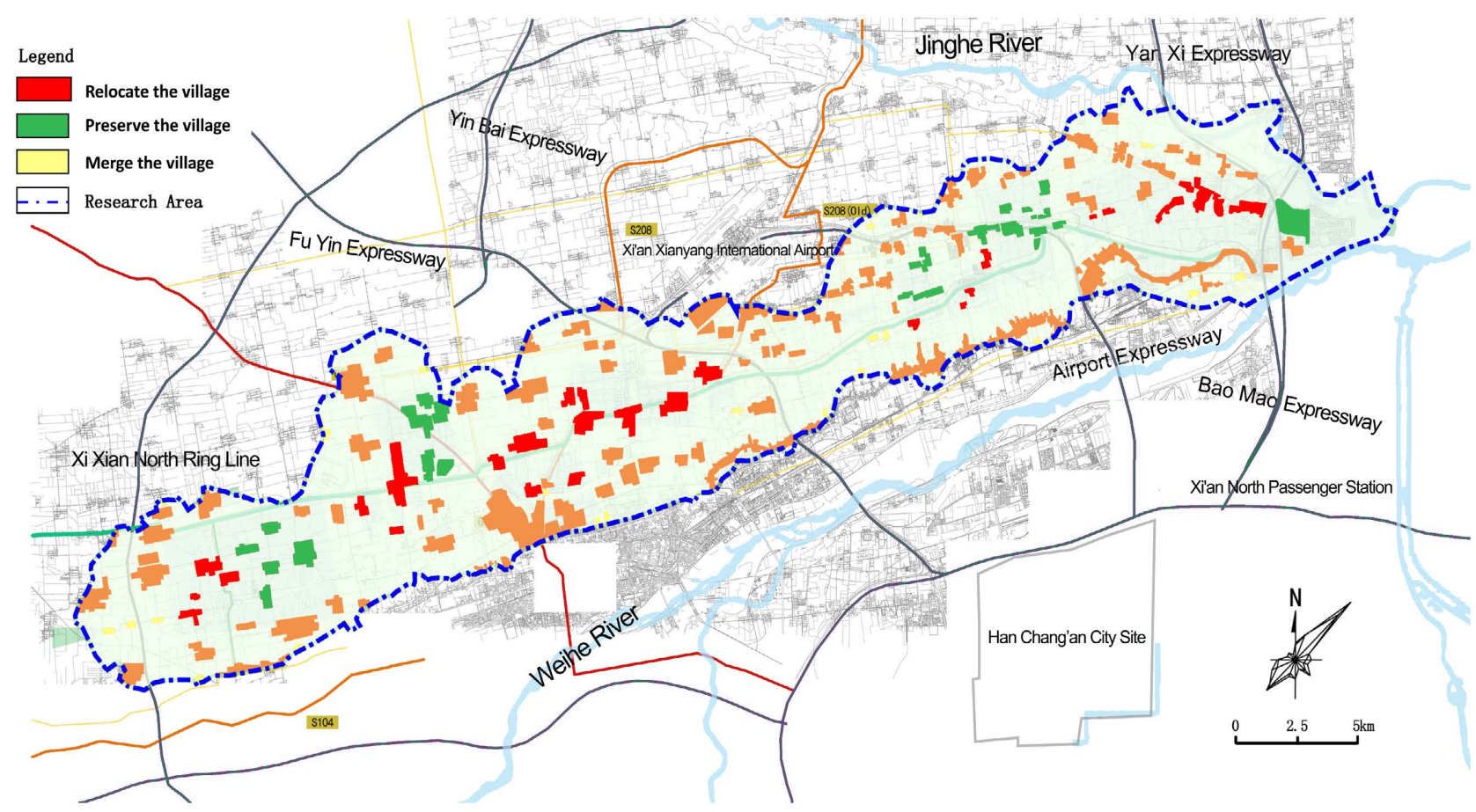

Figure 11. Schematic diagram of village adjustment. Source: authors.

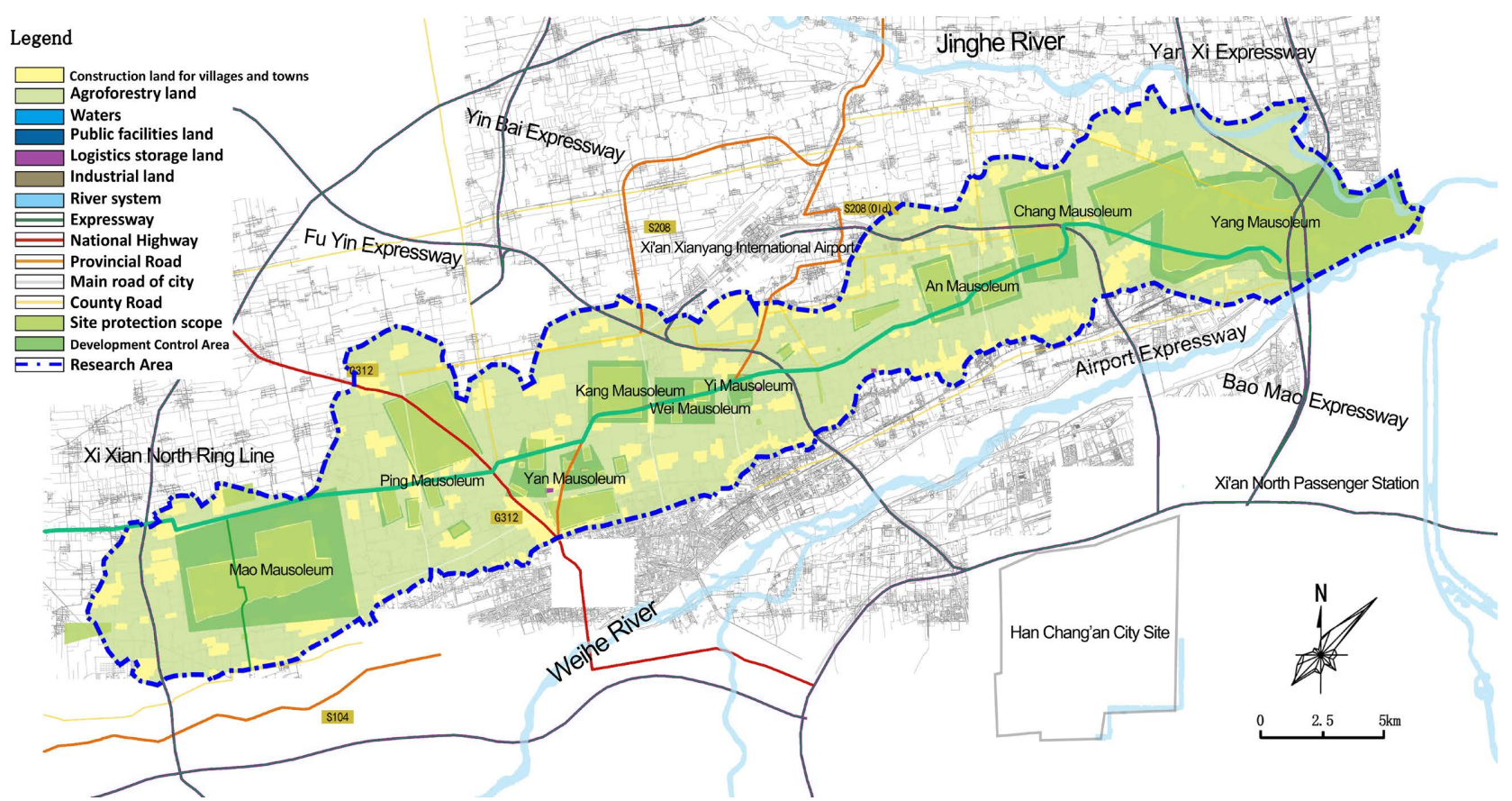

Figure 12. Land use status of the heritage corridor. Source: authors.

The construction of the heritage corridor makes the Western Han Dynasty Mausoleums Region have a relatively complete image. Spatial layout pattern identified as "Four cores, one belt and seven zones" as shown in Figure 13 from the three aspects of heritage protection, production and life function within the scope of the heritage corridor planning. 


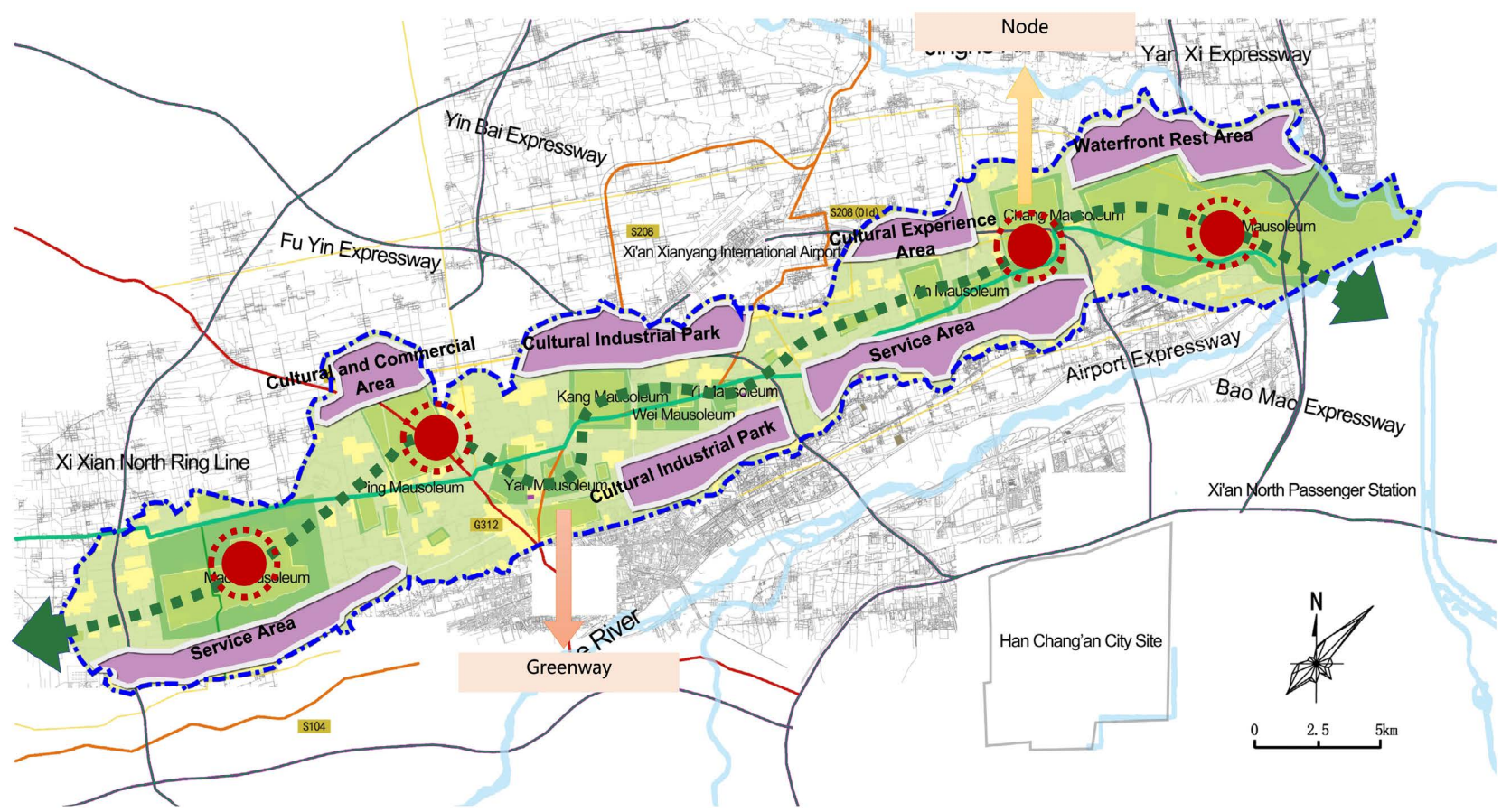

Figure 13. Spatial pattern organization of heritage corridor. Source: authors.

"Four cores" include four culture exhibition centers, which are selected on the basis of heritage score and the convenience of transportation, respectively from the west to the east are Yang Mausoleum, Chang Mausoleum, Ping Mausoleum and Mao Mausoleum.

"One belt" is a green corridor consisting mainly of the site and the agricultural and forestry land, which guides the gathering of the cultural tourism industry through smooth streamlines and perfect functions.

"Seven zones" include seven functional areas, which are designed for cultural commercial district, cultural industrial park, culture experience area and waterfront recreation area respectively from north of the combination of national highway and provincial highway mainly cooperated with the Great Site in cultural activities. Two comprehensive service areas and the central part of the culture industry area are distributed in the south of the site in order to provide service.

\subsubsection{Interpretation System Organization}

The commentary system in this paper is a perfect identification system for increasing dynamic signs, which can guide the guests to understand the history and culture of the corridor and are the main bridges for tourists to deepen the image of the regional impression (Zhu \& Quan, 2015). Organization of the explanation system can make full use of intangible cultural elements such as historical Figures and allusions, literature, folklore, et al. It is necessary to enrich the explanation system forms and connotations by fully excavating the pictures and symbols that with the characteristics of Western Han Dynasty. 
Commentary systems of the Western Han Dynasty Mausoleums should include at least six types, such as tour guide panorama, characters and allusion's introduction boards, scenery introduction boards, road guide signs, warning care boards and service facilities brand name logo, as shown in Table 3.

\subsubsection{Strengthen External Transport Links}

The transportation system is the foundation of the heritage corridor construction. The accessibility of the corridor will determine the tourists' willing to travel, the comfort of travel and the cultural tourism experience. Without affecting the protection of the heritage, the connection with the urban area of Xi'an and Xianyang should be strengthened, and the existing network should be basically kept (Figure 14). In view of the future development of the cultural tourism

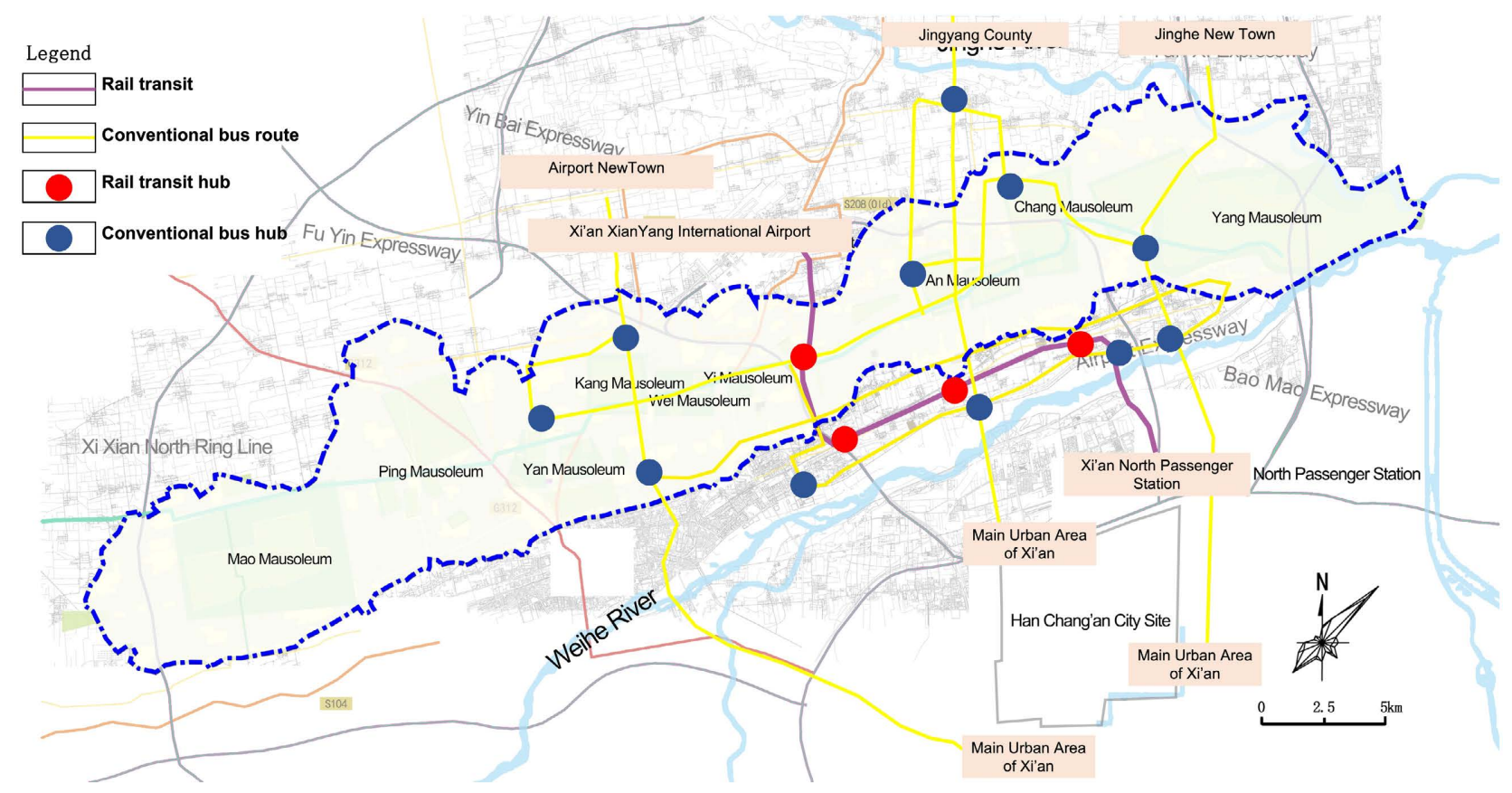

Figure 14. External traffic contact. Source: authors.

Table 3. Commentary system content.

\begin{tabular}{|c|c|c|c|c|c|c|c|}
\hline \multirow{3}{*}{$\begin{array}{c}\text { Explanation Types } \\
\text { Tour Guide } \\
\text { Panorama }\end{array}$} & \multicolumn{7}{|c|}{ Specific Contents } \\
\hline & General & Mausoleum & Text & Notice to & Scenic Spots & Service & \\
\hline & Layout & Pattern & Introduction & Visitors & Information & Phone & \\
\hline $\begin{array}{c}\text { Scenery } \\
\text { Introduction }\end{array}$ & $\begin{array}{l}\text { Introduction } \\
\text { of } \\
\text { Scenic Spots }\end{array}$ & $\begin{array}{l}\text { Introduction of } \\
\text { relevant origins } \\
\text { and allusions }\end{array}$ & $\begin{array}{c}\text { Scenic } \\
\text { Spot Card }\end{array}$ & $\begin{array}{l}\text { Regional Tour } \\
\text { Guide Map }\end{array}$ & & & \\
\hline Road Guidance & Road Sign & Toilet Sign & Parking Sign & & & & \\
\hline Warning Care & Cue Card & Warning Sign & & & & & \\
\hline $\begin{array}{c}\text { Service } \\
\text { Facility Logo }\end{array}$ & Ticket Office & Entrance and Exit & $\begin{array}{l}\text { Tourist } \\
\text { Centre }\end{array}$ & $\begin{array}{l}\text { Medical } \\
\text { Point }\end{array}$ & $\begin{array}{l}\text { Shopping } \\
\text { Centre }\end{array}$ & $\begin{array}{c}\text { Up and } \\
\text { Down Station }\end{array}$ & Toilet \\
\hline
\end{tabular}

Source: authors. 


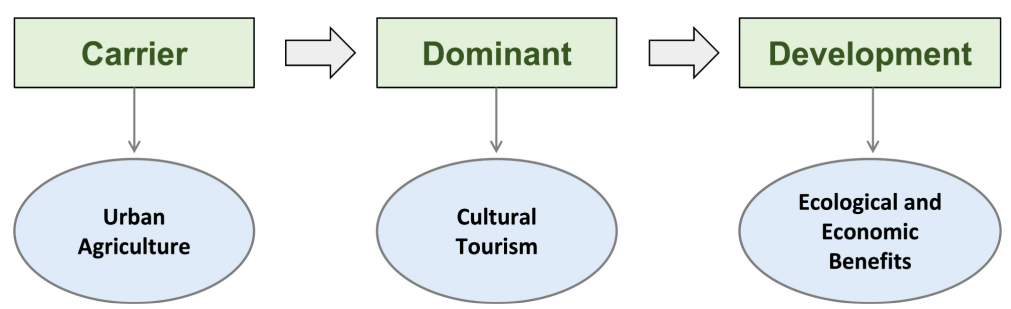

Figure 15. The thought of building greenway. Source: authors.

industry to increase the number of tourists, it is necessary to improve the public transport coverage of the heritage corridor, to set special line for the Western Han Dynasty Mausoleums and to increase the number of transportation hubs at the position in the south side where has a close connection with urban construction area.

\subsection{The Space Organization of the Corridor}

For the Western Han Dynasty Mausoleums Corridor, the construction of continuous sites of green space system is more advantageous for plaque to form unified and continuous base background which plays the role of conserving soil and water, improving the environment.

Due to the contradiction between the protection of the site and the regional development, the study believes that the urban agriculture can be introduced into the green corridor, which can not only meet the ecological benefits, but also create economic value. According to the spatial pattern planned in 5.3 and in combination with the specific characteristics of land using, urban agriculture can be set as the carrier in a business operation pattern with the leading direction of the regional cultural tourism industry in order to increase the regional ecological economic benefits (Figure 15). Carrying out "limit", "preserve" and "update" means on the existing agriculture and forestry, among which, the "limit" on site protection planning scope, the "preserve" on basic farmland protection areas, the "update" on the other land to adjust the existing agricultural, makes full use of agricultural ecological landscape value to establish the ecological agriculture recreational area for the corridor.

\section{Peroration}

Based on the perspective of heritage conservation and regional coordination, this paper determines to use the form of heritage corridor to inspire the vitality of heritage region and to realize the coordination of heritage protection and regional development. The basic conditions of constructing the heritage corridor at the Western Han Dynasty Mausoleums are analyzed, the elements of the heritage corridor system are sorted out from the perspective of landscape ecology and the planning target and planning system of the heritage corridor planning are established. Corresponding to the planning system, the construction of the heritage corridor is studied from "patch-corridor-matrix" levels. 
The main innovation of this paper is three-fold: 1) The use of planning tools to link cultural heritage sites to form heritage corridors, which are mostly linear heritage such as canals and city walls in previous studies; 2) The application of the MCR model to the delineation of corridors, which is more widely adaptable; 3) The combination of ecological concepts and heritage corridor planning, which has certain theoretical support for the new era of territorial spatial planning.

Through further analysis of the research content and methods, the author believes that the article can be improved in the following two aspects: 1) To strengthen the research and discussion of macro-regions, and to further analyze and study the industrial structure. 2) The article uses the MCR model to conduct the suitability analysis of heritage corridors, which mainly measures the influence of environmental elements, and the analysis of the attractiveness of the heritage sources themselves can be added in subsequent studies.

\section{Conflicts of Interest}

The authors declare no conflicts of interest regarding the publication of this paper.

\section{References}

Boley, B. B., \& Gaither, C. J. (2016). Exploring Empowerment within the Gullah Geechee Cultural Heritage Corridor: Implications for Heritage Tourism Development in the Low Country. Journal of Heritage Tourism, 11, 155-176. https://doi.org/10.1080/1743873X.2015.1080712

Chu, J. L., Li, Y., \& Li, J. L. (2019). Present Characteristics and Protection Path of Linear Cultural Heritage Based on "Patch-Corridor-Matrix": A Case of Huizhou Ancient Road. Development of Small Cities \& Towns, 37, 46-52, 60.

Denis, B. (2021). The Heritage Corridor: A Transnational Approach to the Heritage of Chinese Migration. Taylor \& Francis Ltd.

Eugster, J. G. (2003). Evolution of the Heritage Areas Movement. The George Wright Forum, 20, 50-59.

Ewa, B. W., Anna, G., \& Marek, B. (2019). The Role of Trust in Sustainable Heritage Management Networks. Case Study of Selected Cultural Routes in Poland. Sustainability, 11, Article No. 2844.

Ginting, N. (2016). How Self-Efficacy Enhance Heritage Tourism in Medan Historical Corridor, Indonesia. Procedia-Social and Behavioral Sciences, 234, 193-200. https://doi.org/10.1016/j.sbspro.2016.10.234

Gong, D. D., \& Zhang, Q. P. (2014). The National Heritage Corridor (Area) Model Roots and Its Revelation. Urban Planning International, 29, 81-86.

Harkness, T., \& Sinha, A. (2004). Taj Heritage Corridor: Intersections between History and Culture on the Yamuna Riverfront. Places, 16, 62-69.

Li, F. (2016). Corridor Heritage: Temporal and Spatial Evolution and Protection Development Research. Tianjin: Nankai University Press.

Li, H., Wang, W. J., Zhang, Y., Hua, Y. L., \& Li, Y. D. (2020). Research on Ecotourism Carrying Capacity of the "Belt and Road" Heritage Corridor Based on State Space Model. Chinese Landscape Architecture, 36, 18-23. 
Liang, J. (2013). Information Statistics and Analysis Research on the Urban and Rural Planning and Heritage Corridor. Planners, 2, 272-276.

Lindsey, G. (2019). Use of Urban Greenways: Insights from Indianapolis. Landscape and Urban Planning, 45, 145-157. https://doi.org/10.1016/S0169-2046(99)00023-7

Regis, P. (2015). Historical Architectural Heritage and the Scope of Protection. Sino French Seminar on Rural Cultural Heritage: Protection and Development of Ancient Villages in Southern Anhui.

Tang, J. (2016). Industrial Heritage Corridor Construction of the Great Canal: Special Remains of the City Memory-Take Qi Shuyan Area in Changzhou as the Case. Industrial Heritage, 6, 27-36.

Wang, L. Y. (2016). China's Big Site Greening Problems Research. Beijing: Chinese Literature Publishing House.

Wang, Y. Y. (2015). Nanjing Ming City Wall Protection and Build the Corridor Heritage. Jiangsu: Nanjing Forestry University.

Wang, Z. H. F., \& Sun, P. (2001). Heritage Corridor, a Relatively New Method of Heritage Protection. Chinese Landscape Architecture, 17, 85-88.

Wu, X. Y., \& Wang, Y. W. (2020). Temporal and Spatial Differences of Tourism Image Perception of "One Belt One Road" Heritage Corridor in Five Provinces in Northwest China. Areal Research and Development, 39, 86-90, 103.

Xi, X. S., \& Chen, L. (2013). The Erie Canal National Heritage Corridor of Protection and the Sustainable Use of the Method and Its Revelation. Urban Planning International, 4, 104-111.

Yang, T. (2020). On the Construction of National Cultural Heritage Spatial System from the Perspective of Territorial Spatial Planning. Urban Planning Forum, 3, 81-87.

Yang, Y. J., \& Xu, W.M. (2013). Considered the Western Han Dynasty Mausoleums Study on the Relationship between the Building and Natural Environment. Journal of Northwest University Natural Science, 43, 821-825.

Yang, Z. H. F. (2009). Western Han Dynasty Mausoleums Layout Design of the Observation of Weihe River. Cultural Relics, 4, 61-68.

Yu, K. J., Li, W., Li, D. H. et al. (2005). Rapid Urbanization Area Heritage Corridor Suitability Analysis Method to Explore Taizhou, for Example. Geographical Research, 24, 69-76.

Zhan, Q. M., \& Guo, H. G. (2015). Based on GIS and RS Heritage Corridor of the Suitability Analysis Method. Planners, S1, 318-322.

Zhao, Z. H. (2007). A Preliminary Planning of Big City Suburban Site Protection in XianYang of Western Han Dynasty Mausoleums, for Example. Urban Development Studies, 5, 96-100, 118.

Zhong, C. H. (2021). Profound Evaluation and Rediscovery of the Heritage Corridor: Historical Geographical Pre-Exploration and Analysis of Linear Historical Landscape in Japan. Landscape Architecture, 28, 10-14.

Zhu, H. X., \& Quan, D. J. (2015). Great Site Protection and Regional Economic Development, with Palace as an Example. Beijing: Science Press.

Zhu, L. W. (2016). The Cultivation and Optimization Study of the Western Han Dynasty Mausoleums Culture Industry Chain. Master's Thesis, Shaanxi University of Science and Technology. 